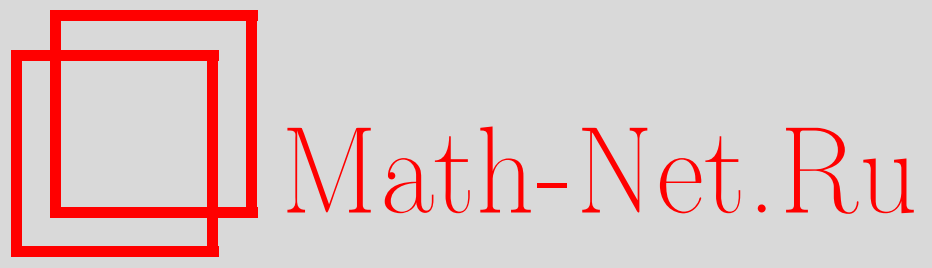

M. Przystalski, A note on a law of iterated logarithm for bounded $N$-demimartingales, Теория вероятн. и ее примен., 2014, том 59, выпуск 1, 197-201

DOI: https://doi.org/10.4213/tvp4559

Использование Общероссийского математического портала Math-Net.Ru подразумевает, что вы прочитали и согласны с пользовательским соглашением http://www . mathnet.ru/rus/agreement

Параметры загрузки:

IP : 54.80 .73 .141

26 апреля 2023 г., 14:28:44

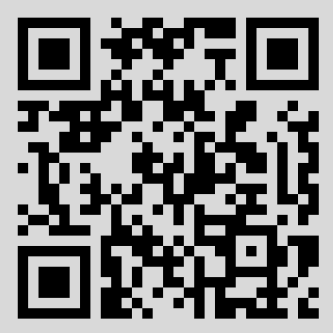




\title{
A NOTE ON A LAW OF ITERATED LOGARITHM FOR BOUNDED $N$-DEMIMARTINGALES
}

\begin{abstract}
Понятие $N$-полумартингала является обобщением понятия отрицательной ассоциированности. Для такого рода случайных величин имеются разнообразные результаты. В настоящей статье доказан закон повторного логарифма для ограниченных $N$-полумартингалов.

Ключевые слова и фразы: случайно взвешенные суммы, сильная сходимость, отрицательно ассоциированные случайные величины, $N$ полумартингал.
\end{abstract}

1. Introduction. Let $\left\{S_{n}, n \geqslant 1\right\}$ be a sequence of random variables defined on a probability space $(\Omega, \mathscr{F}, \mathbf{P})$.

$\mathrm{D}$ e f i $\mathrm{n}$ i t i o $\mathrm{n} 1$. A sequence of $L_{1}$ random variables $\left\{S_{n}, n \geqslant 1\right\}$ is called an $N$-demimartingale if for all $i=1,2, \ldots$

$$
\mathbf{E}\left[\left(S_{i+1}-S_{i}\right) f\left(S_{1}, \ldots, S_{i}\right)\right] \leqslant 0,
$$

for all componentwise nondecreasing functions $f$ provided the expectation is defined. Moreover, if $f$ is assumed to be nonnegative, the sequence $\left\{S_{n}, n \geqslant 1\right\}$ is called an $N$ demisupermartingale.

The notion of an $N$-demimartingale was first introduced by Christofides in [1] as generalization of the concept of negative association which was introduced by Joag-Dev and Proschan in [6]. Over the recent years, various results has been proved. These results are mainly different kinds of inequalities (see, e.g., [1]-[4], [8], [9]), but also strong laws of large numbers [9], and some results concerning complete convergence of $N$-demimartingales [4].

D e f i n i t i o n 2. A finite collection of random variables $X_{1}, \ldots, X_{n}$ is said to be negatively associated if

$$
\operatorname{Cov}\left(f\left(X_{i}, i \in A\right), g\left(X_{j}, j \in B\right)\right) \leqslant 0,
$$

for any disjoint subsets $A$ and $B$ of $\{1, \ldots, n\}$ and for any two componentwise nondecreasing functions $f, g$ on $\mathbf{R}^{A}$ and $\mathbf{R}^{B}$, respectively, provided that the covariance is defined. An infinite collection is negatively associated if for every finite subcollection is negatively associated.

One can easily show that a sequence of partial sums of zero mean negatively associated random variables is an $N$-demimartingale. The class of $N$-demimartingale includes as special case martingales with respect to natural choice of $\sigma$-algebras. Furthermore, it can be shown that a supermartingale is an $N$-demisupermartingale. From the definition of Brownian motion we know that the increments of Brownian motion are independent. The law of iterated logarithm for Brownian motion can be found in [7]. The motivation of this study was a question whether the result for Brownian motion can be extended, under some additional conditions, to the case of $N$-demimartingales. In this paper, we prove the law of iterated logarithm for $N$-demimartingale. As an application of main results we obtain the law of iterated logarithm for randomly weighted partial sums of zero mean negatively associated random variables and the counterpart of the Hardy-Littlewood law of iterated logarithm for empirical distributions of negatively associated random variables.

In this work, we set $\lg x=\ln (\max \{x, e\})$ and $\lg _{2} x=\lg (\lg x)$ and we denote by $C$ a generic positive number that is not necessarily the same at each appearance.

* The Research Center for Cultivar Testing, 63-022 Słupia Wielka, Poland; e-mail: marprzyst@gmail.com 


\section{Results.}

Theorem 1. Let $\left\{S_{n}, n \in \mathbf{N}\right\}$ (with $S_{0} \equiv 0$ ) be an $N$-demimartingale such that for positive numbers $c_{i}, i=1,2, \ldots$,

$$
\left|S_{i}-S_{i-1}\right| \leqslant c_{i}<\infty
$$

Suppose that $\Lambda=\sum_{i=1}^{\infty} c_{i}^{2}<\infty, \mathbf{E} S_{n}=0$ and $\mathbf{E} S_{n}^{2}=\sigma^{2}>0$ for all $n \in \mathbf{N}$. Then

$$
\limsup _{n \rightarrow \infty} \frac{\left|S_{n}\right|}{\sqrt{n \lg _{2} n}} \leqslant 2 \sqrt{2} \Lambda \sigma \quad \text { a.s. }
$$

In the proof of Theorem 1 we use the following exponential inequality for $\mathrm{N}$ demimartingales, which was shown in the proof of Theorem 6 in [2].

Lemma 1. Let $\left\{S_{n}, n \in \mathbf{N}\right\}$ (with $S_{0} \equiv 0$ ) be an $N$-demimartingale with $\mathbf{E} S_{1} \leqslant 0$ and assume that

$$
\left|S_{i}-S_{i-1}\right| \leqslant c_{i}<\infty
$$

where $c_{1}, c_{2}, \ldots$ are positive numbers. Then for any $t>0$ and every $\varepsilon>0$

$$
\begin{gathered}
\mathbf{P}\left(S_{n}>n \varepsilon\right) \leqslant \exp \left(-t n \varepsilon+\frac{t^{2} \sum_{i=1}^{n} c_{i}}{2}\right), \\
\mathbf{P}\left(\left|S_{n}\right|>n \varepsilon\right) \leqslant 2 \exp \left(-t n \varepsilon+\frac{t^{2} \sum_{i=1}^{n} c_{i}}{2}\right) .
\end{gathered}
$$

P r o of of $\mathrm{Th}$ e ore m 1 . Let $Y_{n}=S_{n} / \sigma, n=1,2, \ldots$ In order to prove the theorem we first show that for arbitrarily small $\varepsilon>0$, with probability 1 only at most finitely many events $Y_{n}>2(1+\varepsilon) \sqrt{2 \Lambda n \lg _{2} n}$ occur.

Assume that $\lambda$ is equal to $\sqrt{1+\varepsilon}$, set $n_{k}=\left[\lambda^{k}\right]$, where $[\cdot]$ is the integer part, and let $k_{0}$ be so large that for $k>k_{0}$

$$
n_{k+1}>n_{k}+1, \quad 1<\frac{n_{k+1}}{n_{k}}<\lambda^{2}, \quad 1<\frac{n_{k+1} \lg _{2} n_{k+1}}{n_{k} \lg _{2} n_{k}}<\lambda^{3} .
$$

Let $\left\{Y_{n_{k}}, k \in \mathbf{N}\right\}$ be a subsequence of $\left\{Y_{n}, n \in \mathbf{N}\right\}$. Applying Lemma 1 with $t=$ $\sqrt{\left(2 \lg _{2} n_{k}\right) /\left(\Lambda n_{k}\right)}$, we obtain

$$
\begin{aligned}
\mathbf{P}\left(\left|Y_{n_{k}}\right|>2(1+\varepsilon) \sqrt{2 \Lambda n_{k} \lg _{2} n_{k}}\right) & \leqslant 2 \exp \left(-2(1+\varepsilon) \lg _{2} n_{k}+\frac{\lg _{2} n_{k} \sum_{i=1}^{n_{k}} c_{i}^{2}}{n_{k} \Lambda}\right) \\
& \leqslant 2 \exp \left(-2(1+\varepsilon) \lg _{2} n_{k}+\frac{\lg _{2} n_{k}}{n_{k}}\right) \\
& \leqslant 2 \exp \left(-2(1+\varepsilon) \lg _{2} n_{k}+1\right) \leqslant \frac{C}{k^{2(1+\varepsilon)}}
\end{aligned}
$$

Thus, the series $\sum_{k=1}^{\infty} \mathbf{P}\left(\left|Y_{n_{k}}\right|>2(1+\varepsilon) \sqrt{2 \Lambda n_{k} \lg _{2} n_{k}}\right)$ is convergent for every $\varepsilon>0$ and according to the Borel-Cantelli lemma

$$
\limsup _{n \rightarrow \infty} \frac{Y_{n_{k}}}{\sqrt{2 n_{k} \lg _{2} n_{k}}} \leqslant 2 \Lambda \quad \text { a.s. }
$$

In order to prove that the whole sequence behaves properly, let us denote by $A_{k}(\varepsilon)$ the event

$$
\max _{n_{k} \leqslant j \leqslant n_{k+1}}\left|Y_{j}\right|>2(1+\varepsilon) \sqrt{2 \Lambda n_{k} \lg _{2} n_{k}}
$$

By the Borel-Cantelli lemma, with probability 1, at most finitely many of the events $A_{k}(\varepsilon)$ will occur, once we show that

$$
\sum_{k=1}^{\infty} \mathbf{P}\left(A_{k}(\varepsilon)\right)<\infty
$$


for arbitrarily small $\varepsilon>0$.

Now, by (1), [3, Corollary 8], and the Cauchy-Schwarz inequality, for $k>k_{0}$ we have

$$
\begin{aligned}
\mathbf{P}\left(A_{k}(\varepsilon)\right) & \leqslant \mathbf{P}\left(\max _{1 \leqslant j \leqslant n_{k+1}}\left|Y_{j}\right|>2(1+\varepsilon) \sqrt{2 \Lambda n_{k} \lg _{2} n_{k}}\right) \\
& \leqslant \mathbf{P}\left(\max _{1 \leqslant j \leqslant n_{k+1}}\left|Y_{j}\right|>2 \lambda^{-3 / 2}(1+\varepsilon) \sqrt{2 \Lambda n_{k+1} \lg _{2} n_{k+1}}\right) \\
& \leqslant \frac{C\left(\mathbf{E}\left|Y_{n_{k+1}}\right|^{2}\right)^{1 / 2}}{\sqrt{n_{k+1} \lg _{2} n_{k+1}}}\left(\mathbf{P}\left(\left|Y_{n_{k+1}}\right|>(1+\varepsilon)^{1 / 4} \sqrt{2 \Lambda n_{k+1} \lg _{2} n_{k+1}}\right)\right)^{1 / 2} .
\end{aligned}
$$

By the assumptions, $\mathbf{E}\left|Y_{n_{k+1}}\right|^{2}=1$, and for sufficiently large $k$, we have $n_{k+1} \geqslant \lg _{2} n_{k+1}$. Hence,

$$
\begin{aligned}
\mathbf{P}\left(A_{k}(\varepsilon)\right) & \leqslant \frac{C}{\lg _{2} n_{k+1}}\left(\mathbf{P}\left(\left|Y_{n_{k+1}}\right|>(1+\varepsilon)^{1 / 4} \sqrt{2 \Lambda n_{k+1} \lg _{2} n_{k+1}}\right)\right)^{1 / 2} \\
& \leqslant \frac{C}{\lg k}\left(\mathbf{P}\left(\left|Y_{n_{k+1}}\right|>(1+\varepsilon)^{1 / 4} \sqrt{2 \Lambda n_{k+1} \lg _{2} n_{k+1}}\right)\right)^{1 / 2} .
\end{aligned}
$$

By Lemma 1 and (1) we get

$$
\begin{aligned}
\mathbf{P}\left(A_{k}(\varepsilon)\right) & \leqslant \frac{C}{\lg k} \exp \left(-\frac{t(1+\varepsilon)^{1 / 4} \sqrt{2 \Lambda n_{k+1} \lg _{2} n_{k+1}}}{2}+\frac{t^{2} \sum_{i=1}^{n_{k+1}} c_{i}^{2}}{4}\right) \\
& \leqslant \frac{C}{\lg k} \exp \left(-\frac{t(1+\varepsilon)^{1 / 4} \sqrt{2 \Lambda n_{k} \lg _{2} n_{k}}}{2}+\frac{t^{2} \Lambda}{4}\right) .
\end{aligned}
$$

When

we obtain

$$
t=(1+\varepsilon)^{3 / 4}\left(\sqrt{\frac{2 \lg _{2} n_{k}}{\Lambda n_{k}}}+\frac{\lg _{2} k}{\sqrt{2 \Lambda n_{k} \lg _{2} n_{k}}}\right),
$$

$$
\begin{aligned}
\frac{t^{2} \Lambda}{4} & =\frac{(1+\varepsilon)^{3 / 2}\left(2 \lg _{2} n_{k}+\lg _{2} k\right)^{2}}{8 n_{k} \lg _{2} n_{k}} \leqslant \frac{(1+\varepsilon)^{3 / 2}\left(2 \lg _{2} n_{k}+\lg _{2} k\right)^{2}}{8\left(\lg _{2} n_{k}\right)^{2}} \\
& =\frac{(1+\varepsilon)^{3 / 2}}{2}\left(\frac{2 \lg _{2} n_{k}+\lg _{2} k}{2 \lg _{2} n_{k}}\right)^{2} \leqslant \frac{(1+\varepsilon)^{3 / 2}}{2}\left(1+\frac{\lg _{2} k}{2 \lg k}\right)^{2} \\
& \leqslant 2(1+\varepsilon)^{3 / 2}
\end{aligned}
$$

since $\lg k \geqslant \lg _{2} k$. Hence by (3), we obtain in (2) that

$$
\begin{aligned}
\mathbf{P}\left(A_{k}(\varepsilon)\right) & \leqslant \frac{C}{\lg k} \exp \left(-(1+\varepsilon) \lg (k \lg \lambda)-\frac{1+\varepsilon}{2} \lg _{2} k\right) \\
& =\frac{C}{k^{1+\varepsilon}(\lg k)^{(3+\varepsilon) / 2}} .
\end{aligned}
$$

Thus, the series $\sum_{k=1}^{\infty} \mathbf{P}\left(A_{k}(\varepsilon)\right)$ is convergent for every $\varepsilon>0$ and according to the BorelCantelli lemma,

$$
\limsup _{n \rightarrow \infty} \frac{Y_{n}}{\sqrt{2 n \lg _{2} n}} \leqslant 2 \Lambda \quad \text { a.s. }
$$

Because the collection $\left\{-S_{n}: n \in \mathbf{N}\right\}$ is also $N$-demimartingale, using similar arguments one can show that

$$
\liminf _{n \rightarrow \infty} \frac{Y_{n}}{\sqrt{2 n \lg _{2} n}} \geqslant-2 \Lambda \quad \text { a.s. }
$$

This proves the theorem. 
In case when $\left\{S_{n}, n \in \mathbf{N}\right\}$ is an $N$-demimartingale with uniformly bounded differences, i.e., when $\left|S_{i}-S_{i-1}\right| \leqslant \alpha<\infty$ for $i=1,2, \ldots$, we can prove the following proposition.

Proposition 1. Let $\left\{S_{n}, n \in \mathbf{N}\right\}$ (with $S_{0} \equiv 0$ ) be an $N$-demimartingale with uniformly bounded differences, i.e., for $i=1,2, \ldots$

$$
\left|S_{i}-S_{i-1}\right| \leqslant \alpha<\infty \text {. }
$$

Suppose that $\mathbf{E} S_{n}=0$ for all $n \in \mathbf{N}$. Then

$$
\limsup _{n \rightarrow \infty} \frac{\left|S_{n}\right|}{\sqrt{2 n \lg n}} \leqslant \alpha \quad \text { a.s. }
$$

$\mathrm{P}$ r o o f. Let $a_{n}=\alpha(1+\varepsilon)^{1 / 2} \sqrt{2 n \lg n}$, where $\varepsilon>0$ is arbitrarily small. Then, by Theorem 6 in $[2]$ we obtain

$$
\begin{aligned}
\mathbf{P}\left(S_{n}>a_{n}\right) & \leqslant \exp \left(-\frac{2(1+\varepsilon) \alpha^{2} n \lg n}{2 \alpha^{2} n}\right) \\
& \leqslant \exp (-(1+\varepsilon) \lg n)=n^{-(1+\varepsilon)} .
\end{aligned}
$$

Thus, for every $\varepsilon>0$ the right-hand side converges. Hence, by the Borel-Cantelli lemma it follows that with probability 1 only finitely many events $A_{n}(\varepsilon)=\left\{S_{n}>a_{n}\right\}$ occur, and

$$
\limsup _{n \rightarrow \infty} \frac{S_{n}}{\sqrt{2 n \lg n}} \leqslant \alpha \quad \text { a.s. }
$$

Because the collection $\left\{-S_{n}: n \in \mathbf{N}\right\}$ is also an $N$-demartingale, using similar arguments one can show that

Proposition 1 is proved.

$$
\liminf _{n \rightarrow \infty} \frac{S_{n}}{\sqrt{2 n \lg n}} \geqslant-\alpha \quad \text { a.s. }
$$

3. Applications. Given that the randomly weighted partial sums of zero mean negatively associated random variables form an $N$-demimartingale (see [3, Proposition 9]), we have the following corollary.

Corollary 1. Let $\left\{X_{i}, i \in \mathbf{N}\right\}$ (with $X_{0} \equiv 0$ ) be zero mean sequence of negatively associated random variables with common standard deviation $\sigma$ and such that $\left|X_{i}\right| \leqslant c_{i}$ for all $i \geqslant 1$. Let $\left\{Y_{i}: i \in \mathbf{N}\right\}$ be a sequence of nonnegative, independent, identically distributed, and uniformly bounded random variables such that $Y_{i}$ is independent of $X_{i}$ for all $i \geqslant 1$. Suppose that $\Lambda=\sum_{i=1}^{\infty} c_{i}^{2}<\infty$ and $\mathbf{E}\left|Y_{1}\right|^{2}<\infty$. Then

$$
\limsup _{n \rightarrow \infty}\left|\frac{\sum_{i=1}^{n} Y_{i} X_{i}}{\sqrt{n \lg _{2} n}}\right| \leqslant 2 \sqrt{2 M \Lambda} \sigma\left(\mathbf{E}\left|Y_{1}\right|^{2}\right)^{1 / 2} \quad \text { a.s. }
$$

P r o o f. From Proposition 9 in [3], it follows that sequence of randomly weighted partial sums $S_{n}=\sum_{i=1}^{n} Y_{i} X_{i}$ of zero mean negatively associated random variables is an $N$-demimartingale. By the assumptions,

$$
\left|S_{i}-S_{i-1}\right|=\left|X_{i} Y_{i}\right| \leqslant M c_{i} \quad \text { for all } i \geqslant 1 .
$$

Thus by Theorem 1 we get the assertion.

Corollary 2. Let $\left\{X_{i}, i \in \mathbf{N}\right\}$ be a sequence of negatively associated random variables with common distribution $F$. For a given $x \in \mathbf{R}$, put

$$
F_{n}(x)=\frac{1}{n} \sum_{i=1}^{n} I\left(X_{i} \leqslant x\right)
$$

Then

$$
\limsup _{n \rightarrow \infty}\left|\frac{F_{n}(x)-F(x)}{\sqrt{(2 \lg n) / n}}\right| \leqslant 1 \quad \text { a.s. }
$$


P r o o f. By a fundamental property of negatively associated random variables, for a given $x \in \mathbf{R}$, sequence $\left\{I\left(X_{n} \leqslant x\right), n \in \mathbf{N}\right\}$ is also negatively associated. Furthermore, we have that

$$
\left|S_{i}-S_{i-1}\right|=\left|I\left(X_{i} \leqslant x\right)-F(x)\right| \leqslant 1 \quad \text { for all } i \geqslant 1 .
$$

Thus, by Proposition 1 we get the assertion.

Acknowledgments. I would like to express my gratitude to the referee for the careful reading and valuable comments and remarks.

\section{СПИСОК ЛИТЕРАТУРЫ}

1. Christofides T.C. Maximal inequalities for $N$-demimartingales. - Arch. Inequal. Appl., 2003, v. 1, № 3-4, p. 397-408.

2. Christofides T. C., Hadjikyriakou M. Exponential inequalities for $N$-demimartingales and negatively associated random variables. - Statist. Probab. Lett., 2009, v. 79, № 19, p. 2060-2065.

3. Christofides T.C., Hadjikyriakou M. Maximal and moment inequalities for demimartingales and $N$-demimartingales. - Statist. Probab. Lett., 2012, v. 82, №3, p. 683-691.

4. Hadjikyriakou M. Marcinkiewicz-Zygmund inequality for nonnegative $N$-demimartingales and related results. - Statist. Probab. Lett., 2011, v. 81, №6, p. 678-684.

5. Hu S., Wang $X$., Yang W., Wang $X$. Some inequalities for demiratingales and $N$ demimartingales. - Statist. Probab. Lett., 2012, v. 82, № 2, p. 232-239.

6. Joag-Dev K., Proschan F. Negative association of random variables with applications. - Ann. Statist., 1983, v. 11, p. 286-295.

7. Ламперти Дж. Случайные процессы: обзор математической теории. Киев: Вища школа, 1983, 224 с.

8. Prakasa Rao B.L.S. On some maximal inequalities for demisubmartingales and $N$ demisupermartingales. - J. Inequal. Pure Appl. Math., 2007, v. 8, № 4, Article 112, $17 \mathrm{p}$.

9. Wang X., Hu S., Prakasa Rao B.L.S., Yang W., Maximal inequalities for $N$ demimartingale and strong law of large numbers. - Statist. Probab. Lett., 2001, v. 81, № 9, p. 1348-1353.

Поступила в редакцию

26.VII.2012

Исправленный вариант

4.III.2013 